\title{
Uma Abordagem Gamificada para o Ensino de Lógica de Programação: relato de experiência
}

\author{
Carina Machado de Farias ${ }^{12}$, Fellipe Pereira Azevedo ${ }^{1}$, José Elias de Jesus Dias ${ }^{1}$ \\ ${ }^{1}$ Instituto Federal de Educação, Ciência e Tecnologia da Bahia (IFBA) \\ Av. Centenário, 500, Nazaré - Jacobina - Bahia, 44700-000, Brasil \\ ${ }^{2}$ Pesquisadora do Grupo de Pesquisa Automação, Eficiência Energética e Produção \\ carina.farias@ifba.edu.br, azevedofellipe16, elias.uzumak\{@gmail.com \}
}

\begin{abstract}
The introductory course in Programming Logic is the basis for the training of students in technical and superior courses in the area of Computing. Assimilating the content covered in this course requires students a new way of thinking and skills that are normally not developed in regular education. As a result, the discipline has high rates of disapproval and withdrawal, and is usually one of the disciplines that fail most in these courses. The concern with high failure rates and avoidance in this discipline has led teachers and researchers to seek suitable alternatives for the traditional way of teaching algorithms and programming, where the student is the passive agent of learning, and the teacher is the agent that transmits the contents. In this context, the present work presents a proposal of gamification of the discipline Logic of Programming and reports the results obtained with application of the proposal in a class of the Technical Course of Informatics, of the IFBA, Jacobina campus.
\end{abstract}

Resumo. A disciplina introdutória de Lógica de Programação constitui a base de formação dos estudantes dos cursos técnicos e superiores da área de Computação. Assimilar os conteúdos abordados nessa disciplina requer dos estudantes uma nova forma de pensar e habilidades que normalmente não são desenvolvidas no ensino regular. Como resultado, a disciplina apresenta altos índices de reprovação e desistência, sendo normalmente uma das disciplinas que mais reprova nesses cursos. A preocupação com as altas taxas de reprovação e evasão nesta disciplina tem levado professores e pesquisadores a buscarem alternativas à forma tradicional de ensino de algoritmos e programação, onde o aluno é o agente passivo da aprendizagem, e o professor o agente transmissor dos conteúdos. Nesse contexto, o presente trabalho apresenta uma proposta de gamificação da disciplina Lógica de Programação e reporta os resultados obtidos com aplicação da proposta em uma turma do Curso Técnico de Informática, do IFBA, campus Jacobina.

\section{Introdução}

A disciplina Lógica de Programação, presente nas primeiras etapas dos cursos técnicos e superiores da área de Computação, constitui a base de formação dos estudantes, requerendo deles uma nova forma de pensar e habilidades que dificilmente são desenvolvidas no ensino regular, levando os estudantes a terem grandes dificuldades e, consequentemente, apresentarem baixo rendimento durante o curso (GUEDES, 2014).

Em um estudo realizado na Universidade de São Paulo, Bosse e Gerosa (2015) apontam que o índice de reprovação na disciplina Introdução a Programação, foi de 30\%, sendo que em vários casos ultrapassaram os 50\%, considerando os anos de 2010 a 2014. 
Concluíram ainda que mais de $25 \%$ dos alunos aprovados neste período fizeram 2 ou mais vezes a disciplina. Comparando-se com disciplinas do mesmo semestre, nos cursos de computação, Introdução à Programação é uma das que mais reprova.

A origem do problema das reprovações e evasões na disciplina Lógica de Programação diz respeito a alunos, professores e até mesmo às metodologias utilizadas, sendo possível destacar alguns fatores que contribuem para o cenário atual, tais como: precária base lógico-matemática dos alunos; falta de dedicação aos estudos; limitações do professor; material didático de apoio e metodologia de ensino ineficientes; etc.

Considerando a importância dessa problemática e buscando alternativas para minimizar o número de reprovações e abandonos, muitos professores e pesquisadores têm buscado apoio na gamificação, visando engajar e motivar os alunos e, consequentemente, aumentar seu rendimento e melhorar seu aprendizado. No decorrer da execução desse projeto foram encontrados alguns trabalhos que tratam da inclusão de elementos de jogos em disciplinas como forma de motivar os alunos e alcançar melhores resultados (DA SILVA FIGUEREDO et al., 2015), (MAEKAWA et al., 2015), (JUCÁ et al., 2014), (AGUIAR, 2015).

Segundo Fardo (2013), gamificação, tradução do termo gamification, criado pelo programador britânico Nick Pelling em 2003, consiste no uso de elementos, mecanismos, dinâmicas e técnicas de jogos na rotina profissional, escolar e social do indivíduo num contexto fora do jogo, com o objetivo de incrementar a participação e gerar engajamento e comprometimento por parte dos usuários e maior interação entre as pessoas e empresas com base na oferta de incentivos que estimulam a colaboração entre os envolvidos, para que realizem de forma mais prazerosa suas tarefas.

No ambiente escolar, gamificar é a arte de ensinar conteúdos didáticos através de jogos. Essa é uma técnica muito utilizada nos EUA e que no Brasil, começa a receber a devida atenção. A utilização de jogos, sejam eles virtuais ou não, incentiva o aprendizado de forma interativa e divertida. Dessa forma, a gamificação surge no cenário educacional brasileiro como uma ferramenta capaz de combater a falta de interesse e a dispersão dos alunos em sala de aula.

Neste trabalho, a gamificação foi utilizada na disciplina Lógica de Programação, do Curso Técnico Subsequente de Informática, do IFBA, campus Jacobina, com a finalidade de promover o engajamento dos alunos com relação à matéria, mediado por elementos de games que possam auxiliar nesse processo. Nesse contexto, a gamificação foi também utilizada com o intuito de desenvolver nos alunos o hábito de estudar regularmente, uma vez que a disciplina apresenta conteúdos de caráter cumulativo, de forma que estudar de forma contínua poderia auxiliar os alunos a terem um melhor desempenho na resolução dos exercícios propostos ao longo da disciplina, e com isso aumentar o número de aprovações apresentados na disciplina.

\section{A Disciplina Lógica de Programação}

No Curso Técnico de Informática analisado, Lógica de Programação é uma disciplina obrigatória e presencial, com carga horária total de $60 \mathrm{~h}$, ofertada aos alunos ingressantes no primeiro semestre. O curso é composto por 04 semestres, sendo a disciplina Lógica de Programação, a primeira das 04 disciplinas de programação ofertadas no decorrer do curso.

Embora ministrada por diferentes professores, a metodologia padrão de ensino dessa disciplina entre 2013 e 2016 foi baseada na exposição dos conteúdos, seguido da aplicação de 
listas de exercícios, resolvidos utilizando o computador. As avaliações eram baseadas em listas de exercícios, desenvolvidas em grupos, ou provas individuais no computador.

As taxas de reprovação registradas na disciplina superaram os $90 \%$, como apresentado na Tabela 01 , fato que incomodou os autores desse trabalho, fazendo-os buscarem alternativas que possibilitassem reduzir essas taxas.

Tabela 01: Aprovações e Reprovações na Disciplina Lógica de Programação

\begin{tabular}{|c|c|c|c|c|}
\hline INGRESSO & INICIANTES & APROVADOS & REPROVADOS & $\begin{array}{c}\text { TAXA DE } \\
\text { REPROVAÇÃO }\end{array}$ \\
\hline 2013.2 & 42 & 18 & 24 & $57,14 \%$ \\
\hline 2014.2 & 42 & 15 & 27 & $64,28 \%$ \\
\hline 2015.2 & 37 & 03 & 34 & $91,89 \%$ \\
\hline 2016.2 & 50 & 26 & 24 & $48 \%$ \\
\hline 2017.2 & 31 & 18 & 13 & $41,93 \%$ \\
\hline
\end{tabular}

A partir dessa inquietação, surgiu a proposta de gamificação da disciplina, como uma tentativa de ampliação das taxas de aprovação na disciplina. Tal proposta é apresentada na próxima seção.

\section{Proposta de Gamificação da Disciplina}

A fim de inserir o conceito de gamificação na disciplina Lógica de Programação, foi criado um jogo conceitual intitulado "Quem quer ser Programador?"1, com a proposta de auxiliar no engajamento dos alunos, e conseqüente melhorar seu desempenho na disciplina.

Para tornar a estratégia adotada mais próxima de um jogo real foi criada uma nomenclatura, para que o aluno pudesse se sentir participando de um game. A nomenclatura estabelecida é apresentada no Quadro 01.

\section{Quadro 01: Nomenclatura do Jogo}

\begin{tabular}{|l|l|}
\hline Termo Tradicional & Termo Equivalente \\
\hline Disciplina Lógica de Programação & Jogo Quem Quer ser Programador \\
\hline Aula & Treinamento \\
\hline Aluno & Jogador \\
\hline Professor & Mestre Programador \\
\hline Notas & Bytes \\
\hline Exercício & Batalha Amigável \\
\hline Avaliação & Batalha Mortal \\
\hline Avaliação de Recuperação & Batalha de Recuperação \\
\hline Prova & Missão \\
\hline
\end{tabular}

\footnotetext{
${ }^{1}$ Documento de Regras do Jogo, disponível em https://is.gd/q2ZtHQ.
} 
O jogo foi concebido em 05 fases, cada fase com sua duração previamente definida e uma pontuação máxima de Bytes a ser conquistada, conforme apresentado na Tabela 02.

Tabela 02: Detalhamento das Fases do Jogo

\begin{tabular}{|c|l|c|}
\hline Fase & Denominação & Pontuação Máxima \\
\hline 1 & Quero ser Estagiário & 100 Bytes \\
\hline 2 & Quero ser Trainee & 150 Bytes \\
\hline 3 & Quero ser Programador Junior & 200 Bytes \\
\hline 4 & Quero ser Programador Pleno & 250 Bytes \\
\hline 5 & Quero ser Programador Sênior & 300 Bytes \\
\hline \multicolumn{2}{r}{ TOTAL } & 1000 Bytes \\
\hline
\end{tabular}

O objetivo do jogo é que o jogador acumule Bytes suficientes para se tornar um programador sênior. Cada 100 Bytes conquistados no jogo equivale a 1 ponto na disciplina, de forma que ao final do jogo foi possível converter a pontuação do jogador em nota. Para obter aprovação na disciplina o jogador precisava acumular no mínimo 600 Bytes dos 1000 Bytes possíveis.

Em cada fase, foram propostos treinamentos, batalhas e missões para o jogador conquistar Bytes e alcançar o objetivo do jogo. Ao final do jogo, somou-se a quantidade de Bytes que o jogador obteve em cada uma das fases, de forma a obter a pontuação total do jogador. Tal pontuação foi utilizada para definir o nível que o jogador alcançou no jogo, conforme previsto no Quadro 02.

\section{Quadro 02: Quantidade de Bytes Necessários para alcançar cada Nível}

\begin{tabular}{|c|c|}
\hline Nível & Pontuação Alcançada \\
\hline Estagiário & 0 a 100 Bytes \\
\hline Programador Trainee & 101 a 250 Bytes \\
\hline Programador Júnior & 251 a 450 Bytes \\
\hline Programador Pleno & 451 a 700 Bytes \\
\hline Programador Sênior & 701 a 1000 Bytes \\
\hline
\end{tabular}

Os conteúdos previstos no plano da disciplina foram distribuídos entre as fases do jogo, de forma que para cada fase, foi previsto um conjunto de conteúdos previamente selecionados a serem trabalhados com a turma, como mostra o Quadro 03. 
Quadro 03: Distribuição dos Conteúdos entre as Fases do Jogo

\begin{tabular}{|c|c|c|}
\hline Fase & Denominação da Fase & Conteúdos \\
\hline 1 & Quero ser Estagiário & Lógica, Algoritmos e Linguagem Algorítmica \\
\hline 2 & Quero ser Trainee & $\begin{array}{c}\text { Variáveis e Constantes, Comandos de } \\
\text { Entrada e Saída de Dados, Operadores } \\
\text { Aritméticos, Comandos de Atribuição, } \\
\text { Estrutura Sequencial }\end{array}$ \\
\hline 3 & Quero ser Programador Junior & $\begin{array}{c}\text { Operadores Lógicos e Relacionais, Estruturas } \\
\text { de Seleção (Condicionais) }\end{array}$ \\
\hline 4 & Quero ser Programador Pleno & Estruturas de Repetição \\
\hline 5 & Quero ser Programador Sênior & Ponteiros, Vetores, Matrizes e Arquivos \\
\hline
\end{tabular}

\subsection{Elementos de Games Presentes na Proposta}

Elementos de game são mecanismos presentes em jogos com o objetivo de promover uma experiência lúdica ao jogador durante o jogo (Fardo, 2013). Em vista dessa definição, as seções a seguir apresentam os elementos de game identificados no jogo "Quem Quer ser Programador?". Cada elemento é conceituado, e a forma como o elemento se apresenta no jogo é discutida.

\section{Objetivo}

Todo jogo precisa ter um objetivo bem definido, sem ambigüidades. $\mathrm{O}$ objetivo do jogo define o propósito e o resultado a ser alcançado no jogo. A proposta do jogo "Quem quer ser Programador?" definiu que o objetivo do jogador era acumular o máximo de bytes possível e, com isso, chegar ao nível de Programador Sênior. É um objetivo bem definido e absoluto, não permitindo interpretações ambíguas por parte do jogador, o que faz com que o entendimento acerca da meta principal do jogo fique mais clara.

\section{Regras}

As regras definem como o jogador deve jogar, estabelecendo restrições sobre as ações do jogador. É necessário, portanto, compreender as regras do jogo para estar apto a jogar. As regras do jogo "Quem que ser Programador?" foram estabelecidas em um documento, compartilhado com todos os jogadores antes do início do jogo, de forma que todos tiveram acesso às regras, estando, portanto, aptos a jogar. $\mathrm{O}$ quadro 04 apresenta um trecho do documento de regras do jogo, descrevendo parcialmente as regras para a primeira fase.

\section{Quadro 04: Trecho do Documento de Regras do Jogo}

A fase 1 é composta por 03 treinamentos. A presença em cada treinamento pontua 1 Byte.
Nessa fase são realizadas 03 batalhas amigáveis. Essas batalhas servem para fortalecer o
conhecimento de cada jogador. Em cada batalha amigável que o jogador participa ele pontua 4
Bytes.




\section{Recompensas}

São elementos fundamentais de um jogo. São gratificações que os jogadores recebem para estimular e motivar a realização das atividades. Em todas as 05 fases de "Quem quer ser Programador?" as recompensas se apresentam na forma de direitos adquiridos, ou seja, o jogador adquire direitos durante o jogo caso realize uma determinada ação durante o jogo. $\mathrm{O}$ quadro 05 destaca um exemplo de recompensa presente na fase 3, "Quero ser Programador Júnior".

\section{Quadro 05: Exemplo de Recompensa presente na Fase 03 do Jogo}

Ao final desta fase, os jogadores que conquistarem 120 Bytes, ou mais, recebem como recompensa o direito de escolher entre dois problemas qual prefere resolver durante o desafio parcial da fase seguinte.

\section{Feedback}

Feedback é um elemento de jogo que possibilita a visualização da evolução do jogador diante do objetivo do jogo. A cada missão cumprida ou batalha travada, os resultados da missão ou batalha eram inseridos no Canvas $^{2}$, na forma de um placar, de forma que o jogador podia acompanhar a sua evolução no jogo.

\section{Níveis}

Um jogo pode ser subdividido em níveis de forma que o objetivo principal do jogo é quebrado em vários objetivos menores. O jogador muda de nível à medida que cumpre os requisitos previstos no nível anterior. "Quem quer ser Programador?" foi projetado para acontecer em 05 etapas, conforme consta na Tabela 01, sendo que o nível de dificuldade dos conteúdos abordados em cada etapa é crescente, devendo o jogador percorrer o caminho que se inicia no nível mais básico, "Quero ser Estagiário", até chegar ao nível mais avançado, "Quero ser Programador Sênior”.

\section{Pontuação}

Representa a progressão do jogador no jogo de maneira numérica. A pontuação permite que o jogador saiba até onde ele conseguiu chegar no jogo. Em "Quem quer ser Programador?" a pontuação foi definida a partir do acúmulo de Bytes, onde a quantidade de Bytes acumulada indica o nível alcançado pelo jogador, como pode ser observado no Quadro 02 .

\section{Erro}

Durante um jogo os jogadores têm que superar desafios. Eventualmente, não obtêm êxito e tentam novamente. No jogo "Quem quer ser Programador?" o elemento "erro no processo" está caracterizado pelas "Batalhas de Recuperação", que permitem aos jogadores tentar de novo, com o objetivo de recuperar os pontos perdidos em uma batalha mortal. $\mathrm{O}$ jogador que não obteve êxito em alguma Batalha Mortal poderá participar das batalhas de recuperação e resgatar os pontos perdidos.

\section{Execução da Proposta}

A introdução da gamificação na disciplina de Lógica de Programação foi executada na turma ingressante no segundo semestre de 2017 do Curso Técnico de Informática do IFBA, campus, Jacobina. Haviam 31 alunos matriculados na turma, entretanto, 08 alunos, embora

\footnotetext{
${ }^{2}$ Ambiente virtual de aprendizagem, disponível em https://canvas.instructure.com.
} 
matriculados, nunca assistiram a nenhuma aula. No decorrer do semestre outros 03 alunos evadiram, de forma que no final do período a turma tinha apenas 20 alunos.

No primeiro dia de aula, os alunos foram submetidos a um questionário ${ }^{3}$, buscando identificar o perfil da turma em relação ao hábito de jogar. 19 alunos responderam ao questionário, o que correspondeu a $82,6 \%$ da turma inicial de 23 alunos.

Em relação à idade dos alunos, percebeu-se a predominância de um público jovem, com idade entre 17 e 22 anos. Essa foi uma informação relevante, uma vez que se trata de um público normalmente inserido na cultura dos jogos.

Outras duas informações extraídas dos questionários apontaram que existia chance de sucesso em aplicar a gamificação nessa turma, uma vez que mais de $60 \%$ dos indivíduos indicaram já ter jogado mais de 10 jogos no decorrer de sua vida, ao mesmo tempo em que mais de $60 \%$ da turma afirmou que costuma dedicar entre 1 e 7 h do seu tempo semanal aos jogos.

Por fim, uma última contribuição dos questionários foi a respeito das expectativas dos alunos em relação à introdução da gamificação na disciplina. Quase $100 \%$ dos alunos esperava que a disciplina se tornasse mais fácil, enquanto mais de $50 \%$ tinha a expectativa de se sentirem mais motivados. Esses resultados congraçaram com os objetivos do projeto de motivar e melhorar o desempenho dos alunos.

Diante da análise dos questionários, o perfil dos alunos foi traçado, e concluiu-se que a turma selecionada era adequada à proposta do projeto, por ser uma turma jovem, afinada com os games, e com boas expectativas acerca do formato diferente utilizado na disciplina.

O ambiente do jogo foi o Laboratório de Informática, entretanto, o ambiente virtual Canvas foi também utilizado a fim de facilitar a comunicação entre o professor da disciplina e os alunos. No Canvas, a professora criou a disciplina virtualmente, inseriu os alunos participantes, e no decorrer do semestre disponibilizou o material de treinamento, bem como as batalhas e missões a serem travadas pelos jogadores, sendo possível também ter uma visão geral da realização das tarefas de cada aluno e da turma como um todo. Além da professora, cada aluno participante tinha também uma conta no ambiente virtual, sendo possível acessar o material disponibilizado pela professora, enviar suas respostas às batalhas e missões, além de acompanhar seu desempenho, consultar sua pontuação e, consequentemente, o nível alcançado no jogo.

No decorrer do jogo os jogadores participaram de 20 treinamentos, ocorridos no Laboratório de Informática, 12 batalhas amigáveis, 16 batalhas mortais (e 16 batalhas de recuperação) e 05 missões, disponibilizadas através do Canvas.

20 jogadores jogaram até o final do jogo, sendo que $60 \%$ alcançou o nível máximo previsto, que é o nível de Programador Sênior, como mostra a Tabela 03.

Tabela 03: Nível alcançado pelo jogador de acordo com sua pontuação

\begin{tabular}{|l|c|}
\hline Nível Alcançado & Quantidade de Alunos \\
\hline Estagiário & 1 \\
\hline Trainee & 1 \\
\hline Programador Junior & 1 \\
\hline Programador Pleno & 5 \\
\hline Programador Sênior & 12 \\
\hline Total & 20 \\
\hline
\end{tabular}

\footnotetext{
${ }^{3}$ Questionário de identificação do perfil do aluno, disponível em https://is.gd/PozaSR.
} 


\section{Resultados e Discussões}

A inclusão de elementos de games na disciplina Lógica de Programação, do curso Técnico Subsequente de Informática, do IFBA, campus Jacobina, foi realizada buscando alcançar os seguintes objetivos:

i. Engajar/motivar os alunos a ter melhor desempenho na disciplina;

ii. Desenvolver nos alunos o hábito de estudar regularmente; e

iii. Aumentar o número de aprovações apresentados na disciplina.

A fim de verificar se os objetivos foram alcançados, a análise dos resultados foi realizada a partir de duas perspectivas:

i. desempenho dos alunos nas atividades avaliativas propostas na disciplina; e

ii. impressões dos alunos acerca da experiência.

Sob a ótica do desempenho dos alunos, foi possível perceber que o trabalho alcançou seu objetivo de aumentar as taxas de aprovação na disciplina. Esse fato pode ser comprovado através da consulta à Tabela 01, apresentada anteriormente, onde pode-se constatar que a turma de 2017.2, onde a gamificação foi utilizada, apresentou a menor taxa de reprovação, quando comparada às turmas de semestres anteriores.

A fim de buscar verificar se os demais objetivos do projeto foram atingidos, analisouse as impressões dos alunos em relação ao formato adotado na disciplina, a partir da aplicação de um questionário ${ }^{4}$ ao final do período.

Foram obtidas 20 respostas a esse questionário, a partir das quais foi possível constatar que o projeto conseguiu motivar os alunos na disciplina, uma vez que $80 \%$ das respostas qualificaram o formato adotado na disciplina como Muito motivante ou Motivante. Além disso, a maioria (80\%) dos alunos acredita que seria válido aplicar a gamificação em outras disciplinas. Quando perguntados se o formato da disciplina influenciou em sua dedicação aos estudos, $70 \%$ respondeu que sim. 70\% dos alunos também indicaram que acreditam ter tido um melhor aprendizado devido ao formato adotado na disciplina.

Foi possível constatar também, a partir das respostas ao questionário, que a quantidade de horas dedicadas à disciplina girou em torno de 1 a 5 horas semanais, como afirmado por $80 \%$ dos alunos.

A fim de melhorar a proposta para experiências futuras em outras turmas, buscou-se identificar, através das respostas obtidas com a aplicação do questionário, quais os pontos positivos e negativos da proposta, do ponto de vista dos alunos.

Quanto aos elementos de jogo identificados pelos alunos na proposta, desafios foi citado por $90 \%$, seguido por competição, recompensas, progressão, regras e ranking, todos com $70 \%$. Um ponto importante a ser ressaltado nessa questão é que nenhum aluno apontou diversão nem abstração da realidade como elementos presentes no projeto, destacando aspectos que precisam ser revistos em propostas futuras.

Quando questionados sobre os aspectos positivos da metodologia adotada, os alunos apontaram: motivação, dedicação, aprendizado e trabalho em grupo. O depoimento de um aluno, durante a aplicação dos questionários, reflete o entendimento da maioria sobre os fatores positivos da proposta: "Muito estimulante, instiga a competição. Cada problema colocado aos alunos permite evoluir o raciocínio lógico e matemático."

\footnotetext{
${ }^{4}$ Questionário sobre as impressões dos alunos acerca da experiência, disponível em https://is.gd/nf1l11.
} 
Já os pontos negativos identificados foram: pouco estímulo às atividades em grupo, excesso de atividades extra-classe, muita pressão, pouco tempo para o desenvolvimento das tarefas, dificuldade de administração do tempo para dedicar às outras matérias.

Do ponto de vista da professora da disciplina, "o maior ganho obtido com o formato adotado na disciplina foi o empenho dos alunos em resolver as tarefas propostas, além da dedicação semanal ao estudo dos conteúdos. Tal dedicação se refletiu nos melhores índices de aprovação registrados para a disciplina desde 2013", conforme consta na Tabela 01.

Por outro lado, os participantes do projeto, e autores deste artigo consideraram que o planejamento da gamificação, bem como o acompanhamento da realização das tarefas exigiram mais tempo do que o exigido para o planejamento e acompanhamento da disciplina na forma tradicional. $\mathrm{Na}$ opinião dos autores, é necessário ainda buscar uma ferramenta que gerencie melhor a gamificação na disciplina, a fim de se obter melhores resultados. Segundo os autores, o Canvas ajudou, mas não é a ferramenta mais adequada para a proposta, uma vez que não acomoda os conceitos de elementos de games de maneira natural.

\section{Considerações Finais}

Este trabalho apresentou uma proposta de gamificação para uma das disciplinas de maior índice de reprovação em cursos de Computação e áreas afins, a disciplina Lógica de Programação. $\mathrm{O}$ estudo também relatou a experiência da aplicação dessa proposta na turma de 2017.2 do Curso Técnico Subsequente de Informática do IFBA, campus Jacobina.

Apesar de representar um desafio para a docente, a introdução da gamificação na disciplina Lógica de Programação alcançou os seguintes benefícios:

- Empenho dos alunos na disciplina;

- Persuasão dos alunos sobre a importância do hábito de estudar regularmente; e

- Aumento do percentual de aprovados na disciplina.

Por outro lado, a experiência destacou alguns elementos que requerem melhorias, a fim de se obter resultados ainda mais satisfatórios com a gamificação:

- Necessidade de uma plataforma virtual mais adaptada aos conceitos de gamificação e elementos de jogo.

- Inclusão da diversão como elemento do jogo.

- Maior estímulo à colaboração entre os jogadores.

- Redução do número de tarefas extra-classe, a fím de não trazer prejuízos para o desempenho dos alunos em outras disciplinas.

Diante dos aspectos analisados durante o projeto, como trabalho futuro, pretende-se ajustar a proposta de gamificação, introduzindo os aspectos identificados neste estudo, e aplicá-la em outras turmas.

\section{Referências}

AGUIAR, Janderson. Experiência baseada em Gamificação no Ensino sobre Herança em Programação Orientada a Objetos. In: Anais dos Workshops do Congresso Brasileiro de Informática na Educação. 2015. p. 1444.

BOSSE, Yorah; GEROSA, Marco Aurélio. Reprovações e Trancamentos nas Disciplinas de Introdução à Programação da Universidade de São Paulo: Um Estudo Preliminar. In: XXXV CONGRESSO DA SOCIEDADE BRASILEIRA DE COMPUTAÇÃO / XXIII WORKSHOP SOBRE EDUCAÇÃO EM COMPUTAÇÃO, 2015, Recife/PE. Anais do XXXV Congresso da Sociedade Brasileira de Computação. Porto Alegre: Sociedade 
Brasileira de Computação, 2015. Disponível em: $<$ http://www.lbd.dcc.ufmg.br/colecoes/wei/2015/044.pdf>. Acesso em: 06 fev. 2018.

BRAZIL, André; BARUQUE, Lúcia. Gamificação Aplicada na Graduação em Jogos Digitais. In: Brazilian Symposium on Computers in Education (Simpósio Brasileiro de Informática na Educação-SBIE). 2015. p. 677.

DA SILVA FIGUEREDO, K. et al. Uma Abordagem Gamificada para o Ensino de Programação Orientada a Objetos. In: $23^{\circ}$ Workshop sobre Educação em Computação. 2015. Recife, PE: SBC - Sociedade Brasileira de Computação.

FARDO, Marcelo Luís. A gamificação como estratégia pedagógica: estudo de elementos dos games aplicados em processos de ensino e aprendizagem. 2014.

GUEDES, E. Um Estudo Observacional sobre a Disciplina Introdutória de Programação. In: XX Workshop de Informática na Escola. 2014. Dourados, MS: SBC - Sociedade Brasileira de Computação, pp.552-561. Disponível em: http://brie.org/pub/index.php/wie/article/view/3140/2648.

JUCÁ, Paulyne M.; ROLIM, G. Aplicação da Gamificação na Disciplina de Empreendedorismo. In: XXII Workshop sobre Educação em Computação (WEI 2014). 2014.

MAEKAWA, Christian; NAGAI, Walter; IZEKI, Claudia. Relato de Gamificação da disciplina Projeto e Análise de Algoritmos do curso de Engenharia de Computação. In: Anais do Workshop do Congresso Brasileiro de Informática na Educação. 2015. p. 1425. 